\title{
Impact of CRC Energy Efficiency Scheme on Implementing Energy Efficiency Strategies in Existing Buildings
}

\author{
N. Jayaweera ${ }^{1, ~ \# ~ a n d ~ D . ~ C r a w f o r d-B r o w n ~}$ \\ ${ }^{1}$ Dept. of Architecture, University of Moratuwa, Sri Lanka \\ ${ }^{2}$ Dept. of Land Economy, University of Cambridge, United Kingdom \\ \# Corresponding Author: \\ Tele: (+94) 77733 3833; E-mail: nadika1982@yahoo.com
}

\begin{abstract}
The Carbon Reduction Commitment Energy Efficiency scheme (CRC) was introduced in April 2010 as a mandatory carbon emissions reduction policy initiative in the United Kingdom. The CRC is designed to incentivise the implementation of cost-effective energy efficiency strategies (EES) in participating organisations by a combination of behavioural, financial and reputational drivers. Developing strategies for reduction of $\mathrm{CO}_{2}$ emissions in existing buildings is a difficult task due to fact that the decision making processes leading to implementation of EES have many exogenous influences (energy prices, building regulations, building condition, occupant behaviour etc.). The impact of CRC is taken in the context of 9 other exogenous variables influencing the decision making process. An IAD framework is employed to analyse the impact of the CRC in the decision making process for implementing EES in retrofitting of buildings in 16 Colleges of the University of Cambridge, UK. The study concludes that the CRC behavioural driver is most effective, while the financial and the reputational driver do not have the expected impact.
\end{abstract}

KEYWORDS: Carbon Reduction Commitment Energy Efficiency scheme (CRC), Energy efficiency, Existing buildings

\section{Introduction}

The Carbon Reduction Commitment Energy Efficiency scheme (CRC) was introduced in April 2010 as a mandatory carbon emissions reduction policy initiative in the United Kingdom. The scheme targets large commercial and public sector organisations that are not covered by the Climate Change Agreements (CCAs) or the EU Emissions Trading Scheme. The CRC is designed to incentivise the implementation of cost-effective energy efficiency strategies (EES) in participating organisations by a combination of behavioural, financial and reputational drivers. The participating organisations are expected to deliver carbon savings amounting to $4.4 \mathrm{Mt} \mathrm{CO}_{2}$ per year. 
The CRC Registry is maintained by the Environment Agency (EA), where participants register, submit reports, purchase and surrender allowances. Organisations qualify to participate in the scheme, if they had at least one halfhourly electricity meter (HHM), consuming at least $6000 \mathrm{MWh}$ per year as of 2008. Each participant has a web-based account in the CRC registry. Non-compliance with the $\mathrm{CRC}$ will result in financial penalties and possible publication of the failure to comply with the CRC.

Participants have to assess and clearly identify their activities and supplies excluding gas and electricity supplies that are used for domestic or transport purposes. The supplies are classified as "core" or "non-core". A core electricity supply is measured through settled half-hourly meters, non-settled half-hourly meters, and non-domestic meters and dynamic supplies. Non-core electricity includes electricity generated on site, self-supply under CRC or unmetered electricity. Supplies measured through gas meters, other than core supplies, are termed as non-core gas supplies. A list of non-core fuels is given in CRC guidelines by the EA.

The first phase of the CRC came into force from April 2010 to March 2014. There are five mandatory steps for a typical year of compliance. They consist of (1) collating relevant energy supplies (2) reporting $\mathrm{CO}_{2}$ emissions (3) purchasing and surrendering allowances equivalent to CRC emissions (4) keeping records of supplies and other relevant information in the evidence pack and (5) reviewing performance against other CRC participants.

The first phase of CRC operates in two stages. Stage one requires participants to report their $\mathrm{CO}_{2}$ emissions between April and the last working day in July. A Footprint Report is only required for the first reporting year of phase one. The purpose of the Footprint Report is to determine which emissions need to be reported annually. The Footprint Report includes all energy supplies including non-core supplies.

Participants need to submit an Annual Report (online) by the last working day of July after the end of each compliance year. Data for the supplies in the CRC can be obtained by taking meter readings, using invoices from suppliers and by using annual statements from suppliers. If adequate meter readings are unavailable the participant can estimate the energy supply. Estimated supply is defined in the CRC guidelines, as the entire annual supply of electricity or gas if, for a given compliance year, at least half the year's supply can be estimated. An estimated supply is recorded in the "estimated supply" column in the Annual Report and an additional 10 per cent will be applied to account for uncertainties introduced by use of estimated rather than metered consumption.

The CRC supplies are then converted into CRC emissions (in tonnes of $\mathrm{CO}_{2}$ ) using data from the Annual Report based on standard conversion factors for each fuel type. The emissions will be calculated from the supply information entered in the 
Annual Report. CRC organisations have to report more than $90 \%$ of their total footprint emissions in the annual report (known as the $90 \%$ Rule).

The mandatory monitoring and reporting mechanism is the first step of compliance to the $\mathrm{CRC}$ and is the dominant behavioural driver of the scheme. Monitoring and reporting is considered as a behavioural driver in this study because of its potential to motivate building owners and occupants to improve their attitude towards energy efficiency.

In the second stage of Phase I, participants must pay for and surrender allowances to cover their annual CRC emissions in tonnes of $\mathrm{CO}_{2}\left(\mathrm{tCO}_{2}\right)$; this makes the CRC analogous to a cap and trade scheme. The total annual allowances cost will be the cost per allowance for the compliance year multiplied by the quantity of CRC emissions in the Annual Report, which for phase I is set at $£ 12 / \mathrm{tCO}_{2}$. The revenues from the emission allowances were initially expected to be recycled to participants by means of a direct annual payment proportional to average annual emissions with a bonus / penalty depending on the organisation's position in a CRC Performance League Table (PLT) (Department of trade and industry, 2007). However the recycling of the funds was removed before the start of the first phase of the CRC to the dismay of the participants. Many participants expected to be rewarded for their commitment to CRC by being awarded recycled funds proportionate to their standing on the PLT. The government now keeps the revenue collected from the CRC emission allowances.

In the current structure of the CRC the main financial driver is the emission allowances (simply known by the participants as the CRC tax). In order to reduce the CRC tax, organisations may take actions to reduce their energy consumption, or switch to renewable energy sources. Participants will be able to determine their own emissions targets within the scheme. The financial driver of the CRC, allocates a monetary value for $\mathrm{CO}_{2}$ emissions. This may motivate organisations to reduce their energy consumption in order to save on the "CRC tax" if not for altruistic motives for mitigating climate change.

The main reputational driver of the CRC is the PLT, as the ranking of participants is expected to have an impact on the organisation's reputation. The PLT is based on the information provided in the Annual report and consists of ranking the participating organisations based on their commitment to the CRC. For 2010/11, the PLT was based on data for the "Early Action Metric". The Early Action Metric consists of information about early actions taken to improve energy efficiency. This metric will not apply after 2012/13. The "Absolute Metric" refers to annual percentage change in $\mathrm{CRC}$ emissions compared with the historic average. The Growth Metric is the annual percentage change in CRC emissions per unit of turnover/revenue expenditure compared with the historic average. For each year of Phase 1, each of these metrics has a different "weighting" or degree of influence within the PLT. 
However from the 2013/14 reporting year the PLT will be replaced by a list of the participants and their respective $\mathrm{CO}_{2}$ emissions due to the need of simplifying the scheme. For the purpose of the present study, the impact of the PLT as a reputational driver is taken into consideration as the PLT is still in force until the next publication of the list of participants.

In June 2012, as a result of consultation with the participants in order to ensure a cost-effective, workable scheme several amendments were made to the CRC. The consultation document set out 46 proposals (Environmental Agency, UK, 2012) aimed to simplify the scheme. Major changes to be implemented in the future include the introduction of two fixed price sales of allowances a year (one forecast and one retrospective) to replace the auction of allowances in a capped system, reducing the number of fuels reported, using only electricity measured by settled half hourly meters (HHMs) for qualification purposes, ending the requirement for footprint reports, reducing requirements on maintaining records and removing the residual percentage rule ( $90 \%$ rule). As the CRC is mandatory, consultations with the participants resulting in amendments to the CRC are necessary to make the scheme feasible. However as the CRC relaxes restrictions, incentives for improving energy efficiency will also be less attractive. This study aims to understand the impact of the CRC Energy Efficiency Scheme on the decision making process for implementing energy efficiency strategies in existing buildings.

The motivation to carry out this study include, amongst others:

- Policy goals in general are achieved by motivating decision makers to comply with the policy. Therefore to achieve the $\mathrm{CRC}$ goal of $\mathrm{CO}_{2}$ emissions reductions, the $\mathrm{CRC}$ shall influence the decision making process for implementation of EES in participating organisations.

- The nature of decision-making on energy use in buildings requires taking a "bottom-up" approach to identifying the factors influencing energy efficiency, rather than proposing "top-down" prescriptions based on economy-wide data and analysis (WBCSD, 2009). In order to conduct a bottom up analysis the decision making levels of the participating organisational structure must be understood to clarify the roles, responsibilities and influences of decision makers involved in some aspect of EES decisions.

- This study concentrates on implementation of EES in existing buildings because of their role in achieving the national $\mathrm{CO}_{2}$ emissions reductions target in the UK. According to Kelly (2009), unless there is a deep retrofit of existing buildings to reduce carbon emissions by $60 \%$ to $80 \%$, the targets being set in the UK Climate Change Bill will certainly be missed. Therefore policies that are designed to mitigate climate change (including CRC) should address the issues of improving energy efficiency existing buildings in the UK. 
- The CRC does not include emissions from transport; hence most of the savings from the CRC would come from EES in the existing buildings for participants. Therefore the effectiveness of the CRC policy might depend to a large extent on how well the policy can motivate energy efficiency in existing buildings.

\section{Methodology}

The following steps were followed in order to obtain answers to the research question.

As per registration requirement, organisations comply with CRC as a group not by site; therefore understanding the participant organisation structure is the first step leading into analysing the role of the CRC. It is useful to think of decision making in an organisation in different levels because CRC drivers are designed to impact different decision making levels. The behavioural driver (monitoring and collection of data) impacts the operational level, the financial driver (emission allowances) works at the administrative level and the reputational driver (PLT) has implications at the strategic level. Therefore underlying mechanisms of the decision making processes have to be established in order to understand how and when the CRC drivers influence the organisation decision making that leads to implementing EES.

The CRC is just one of many other influential factors in the implementation of EES in existing buildings. In order not to over-estimate the impact of CRC in this study it is important to consider the CRC in the broadest possible context, considering all influencing factors such as occupant behaviour, energy prices, building regulations etc.

As observed by the consultation with participants, the CRC in practice is problematic and less attractive than it is in concept, which is taken into account in the study. Therefore the gaps and inconsistencies of the expected role of CRC in comparison to the actual are discussed using a case study.

\section{The IAD Framework}

Following Ostrom (2005), an Institutional and Analysis Development (IAD) framework is utilised to analyse the impact of a range of exogenous variables on the decision making process. The IAD framework is a multi-tiered conceptual map (Figure 2) consisting of an action arena, the resulting patterns of interactions and outcomes, and evaluating these outcomes (Ostrom, 2005). As Ostrom states when individuals interact in repetitive settings they may be in operational situations that directly affect the world, or they may be making decisions at other levels of analysis that eventually impinge on operational decision making (Ostrom, 2007). Ostrom distinguishes among these levels as operational choice, collective choice and constitutional choice. 
The three levels of the organisational structure (operational, administrative and strategic following the classification by Ansoff, 1969) operate corresponding to choice levels (operational, collective and constitutional) of the IAD framework. In this study the focus is on the identification of the exogenous variables in the IAD framework and not on final outcome evaluation. The identification of the exogenous variables impacting the decision making process was conducted through a literature survey.

Exogenous Variables

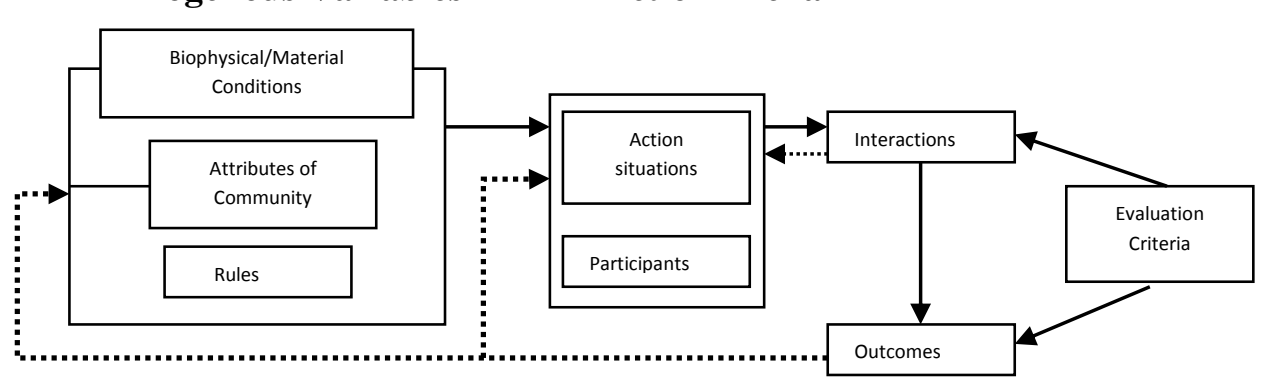

Figure 1: A framework for institutional analysis

Source: Elinor Ostrom, 2005

\section{Action Arena}

The first step in analysing any problem in an IAD framework is to identify a conceptual unit called an action arena (Figure 2). An action situation can in turn be characterised using seven clusters of variables: (1) participants (single or cooperate actors), (2) positions, (3) potential outcomes, (4) action-outcome linkages, (5) the control the participants exercise, (6) types of information generated and (7) the costs and benefits assigned to actions and outcomes (Ostrom, 2005). In this study three action arenas are represented by three separate decision making models for implementing EES in existing buildings. Therefore three decision making models are developed at the operational, administrative and strategic levels respectively.

\section{Exogenous Variables}

In this study following the IAD framework, after developing the decision making processes for the action arena, exogenous variables impacting the action arena are discussed. From this viewpoint, the action arena is now a dependent variable. Exogenous variables are outcomes of another action arena that may be a part of the system that is being analysed or a system that is unrelated. The factors affecting the action arena include three clusters of exogenous variables: (1) the rules used by participants to order their relationship, (2) the attributes of the bio-physical world and (3) the structure of the more general community within which any particular arena is placed (Ostrom, 2005). The IAD framework assigns all relevant exogenous variables and factors to different categories within a foundational structure of logic relationships (McGinnis, 2011). Therefore considering the exogenous variables 
influencing different levels of decision making (taking place in the action arena) an IAD framework is the most appropriate framework of analysis for this study.

\section{Case Study Analysis}

This research study employs the colleges of the University of Cambridge, UK as a case study to analyse the impact of the CRC on the decision making processes of retrofitting existing buildings. The colleges provide accommodation, dining facilities, libraries and other supporting facilities for students who attend the university. The colleges were selected as a case study as they are similar in function, and they all report to the CRC scheme as a single entity. The colleges vary in size as seen in Table 2 . Some colleges are home to buildings that have a national historic importance. Therefore there are many challenges for retrofitting energy efficient strategies in college buildings.

Table 1: Summary of exogenous variables identified at different decision making levels for implementing EES in existing buildings

\begin{tabular}{|c|c|c|}
\hline $\begin{array}{l}\text { Level of } \\
\text { Decision }\end{array}$ & & Exogenous Variables \\
\hline \multirow[t]{4}{*}{$\begin{array}{l}\text { Operational } \\
\text { level }\end{array}$} & $\begin{array}{l}\text { Physical } \\
\text { attributes }\end{array}$ & $\begin{array}{l}\text { Building specific information - The physical attributes } \\
\text { that take a prominent role at the operational level are in } \\
\text { the form of building specific information (geographic } \\
\text { location, weather, building form, microclimate, } \\
\text { construction method size, age etc.). }\end{array}$ \\
\hline & & $\begin{array}{l}\text { Alternative objectives of retrofitting - In many cases } \\
\text { buildings are retrofitted for reasons other than to reduce } \\
\text { energy use. The reason for retrofitting is usually a } \\
\text { requirement in change of the physical form of the } \\
\text { building due to a change in the function or expansion of } \\
\text { existing functions in the building. }\end{array}$ \\
\hline & $\begin{array}{l}\text { Community } \\
\text { attributes }\end{array}$ & $\begin{array}{l}\text { Occupant behaviour - Human interactions with a } \\
\text { building have important implications for a building's } \\
\text { energy use, affecting both the indoor microclimate and } \\
\text { the demands for energy. Therefore predicting building } \\
\text { performance using energy simulation models is only as } \\
\text { good as the prediction of the building's occupant } \\
\text { behaviour (Kwok and Lee, 2011). }\end{array}$ \\
\hline & Rules & $\begin{array}{l}\text { CRC behavioural driver - Monitoring and reporting } \\
\mathrm{CO}_{2} \text { emissions }\end{array}$ \\
\hline
\end{tabular}




$\begin{array}{ll}\text { Administrative } & \begin{array}{l}\text { Physical } \\ \text { level }\end{array} \\ \text { attributes }\end{array}$

Community attributes

Rules

Community attributes

\section{Strategic level Physical factors}

Rules
Energy prices - Rising energy prices are a key driver of decisions for improving energy efficiency especially in the Cost Benefit Analysis stage. If higher energy prices are expected, energy-efficient retrofitting would be an attractive investment opportunity (Amstalden et al., 2007).

Co-benefits - The indirect benefits include the reduction in effects of air pollution caused by burning fossil fuels, the gain in energy independence, the decrease in the greenhouse effect and the reduction in effects on health and on the environment caused by generating nuclear power and disposing of radioactive wastes (Harvey, 1992).

Building regulations and English Heritage - In the Cambridge, UK where many buildings have historical value, strategies for improving energy efficiency may encounter barriers due to regulations on actions that affect historic buildings.

CRC financial driver - CRC emission allowances

Financial/Macro economic factors - Finances shape strategic decisions of organisations in any context. The state of the finances can have varied effects on implementing EES depending on the perspective taken by the organisation. For example in times of global recessions and ensuing public debt crisis, retrofitting buildings can become an energy efficiency cost savings opportunity for organisations (Rysanek and Choudhary, 2012) or may be considered an unnecessary expenditure in a time of difficulty.

Shareholder perceptions on cooperate reputation The dominant view today is that good environmental performance results in improved financial performance; empirical results have been inconclusive and even conflicting, which highlights the complex nature of the link between environmental and financial performance (Jacobs et al., 2010).

HEFCE policies - The Higher Education Funding Council for England (HEFCE) has allocated £20million for energy efficiency measures in universities. HEFCE has also established several guidelines for universities for reducing energy use.

CRC reputational driver - The Performance League Table (PLT) 
Table 2: Background information of the colleges' participating in the research study

\begin{tabular}{|c|c|c|c|c|c|c|c|}
\hline \multirow[b]{2}{*}{ College } & \multirow{2}{*}{$\begin{array}{l}\text { Post of the } \\
\text { Interviewee }\end{array}$} & \multicolumn{2}{|c|}{ Student Population } & \multirow{2}{*}{$\begin{array}{c}\mathrm{CO}_{2} \\
\text { Emissions } \\
\text { by } \\
\text { Electricity } \\
\left(\mathrm{tCO}_{2}\right)\end{array}$} & \multirow{2}{*}{$\begin{array}{c}\mathrm{CO}_{2} \\
\text { Emissions } \\
\text { by Gas } \\
\left(\mathrm{tCO}_{2}\right)\end{array}$} & \multirow{2}{*}{$\begin{array}{c}\text { Total CRC } \\
\text { Allowances } \\
\text { Purchased } \\
\text { (f) }\end{array}$} & \multirow{2}{*}{$\begin{array}{c}\text { Cove } \\
\text {-rage } \\
(\%)\end{array}$} \\
\hline & & $\begin{array}{c}\text { Under } \\
\text { graduates }\end{array}$ & $\begin{array}{c}\text { Post } \\
\text { graduates }\end{array}$ & & & & \\
\hline A & Bursar & 350 & 200 & 730.6 & 993.3 & 20,931 & 91.5 \\
\hline $\mathrm{B}$ & $\begin{array}{l}\text { Domestic } \\
\text { Bursar }\end{array}$ & N/A & 700 & 269.8 & 395.6 & 7,985 & 90 \\
\hline $\mathrm{C}$ & $\begin{array}{l}\text { Junior } \\
\text { Bursar }\end{array}$ & 450 & 220 & 1498.9 & 1218.0 & 32,670 & 90 \\
\hline $\mathrm{D}$ & $\begin{array}{c}\text { Estate } \\
\text { Manager }\end{array}$ & 1150 & 400 & 870.0 & 872.8 & 21,090 & 98.8 \\
\hline $\mathrm{E}$ & $\begin{array}{l}\text { Junior } \\
\text { Bursar }\end{array}$ & 510 & 480 & 1144.2 & 1519.5 & 32,008 & 95 \\
\hline $\mathrm{F}$ & Bursar & 125 & 325 & 407.9 & 320.6 & 8,755 & 91.3 \\
\hline I & Bursar & 85 & 515 & 484.6 & 374.6 & 10,311 & 90 \\
\hline $\mathrm{J}$ & Bursar & 420 & 200 & 1124.1 & 823.3 & 23,382 & 90 \\
\hline $\mathrm{K}$ & $\begin{array}{l}\text { Senior } \\
\text { Bursar }\end{array}$ & 340 & 160 & 649.9 & 623.3 & 20,458 & 90 \\
\hline $\mathrm{L}$ & $\begin{array}{l}\text { Senior } \\
\text { Bursar }\end{array}$ & 440 & 220 & 917.6 & 745 & 20,001 & 90 \\
\hline M & $\begin{array}{l}\text { Junior } \\
\text { Bursar }\end{array}$ & 600 & 300 & 1842.6 & 1927 & 45,243 & 95.2 \\
\hline $\mathrm{N}$ & Bursar & N/A & 230 & 249.6 & 430 & 8,155 & 90 \\
\hline $\mathrm{O}$ & Bursar & 460 & 270 & 1509.7 & 2071.2 & 43,028 & 94.4 \\
\hline $\mathrm{P}$ & Bursar & 330 & 200 & 805.4 & 673.1 & 17,742 & 90 \\
\hline Q & Bursar & 170 & 350 & 702.6 & 700.4 & 15,767 & 94.7 \\
\hline $\mathrm{R}$ & Bursar & 116 & 203 & 339.7 & 275.7 & 7,385 & 90 \\
\hline
\end{tabular}


This study uses the snowball sampling method, selecting 15 bursars and 1 estate manager from the colleges of the University of Cambridge to assess the role of the 9 exogenous variables and $3 \mathrm{CRC}$ drivers. To collect data, a survey was conducted by means of a semi-structured interview. Thus, the elements investigated using the IAD framework formed the questions for the interview. The interviewees are all key personnel involved at the operational, administrative and strategic levels of decision making in the colleges. The questionnaire consisted of 26 questions aimed at producing data for a balanced analysis of the impact of twelve exogenous variables identified in Table 1.

All the interviewees agreed that building specific information (geographic location, weather, building form, microclimate, construction method size, age etc.) is the first consideration in retrofitting existing buildings. $50 \%$ of the respondents agreed that energy efficiency in buildings is not their primary concern (Figure 2). Some of the primary concerns for retrofitting identified during the study were the rolling programme for building renovations, change of function, expansion of space and improving indoor environment. However, all the respondents agreed that energy efficiency is an opportunistic consideration in the retrofitting existing buildings.

Occupant behaviour is considered an essential aspect by the colleges with $78 \%$ (Figure 2) of the respondents agreeing that improving occupant behaviour can reduce energy use. However the colleges do not consider occupant behaviour in their pre-retrofit survey due to difficulty in calculating the impact of occupant behaviour on improving energy efficiency. $46 \%$ of respondents agreed that CRC scheme has a high impact on improving monitoring of energy consumption. Many respondents stated that if it wasn't for the CRC they would not possess the knowledge they have now of their building energy consumption.

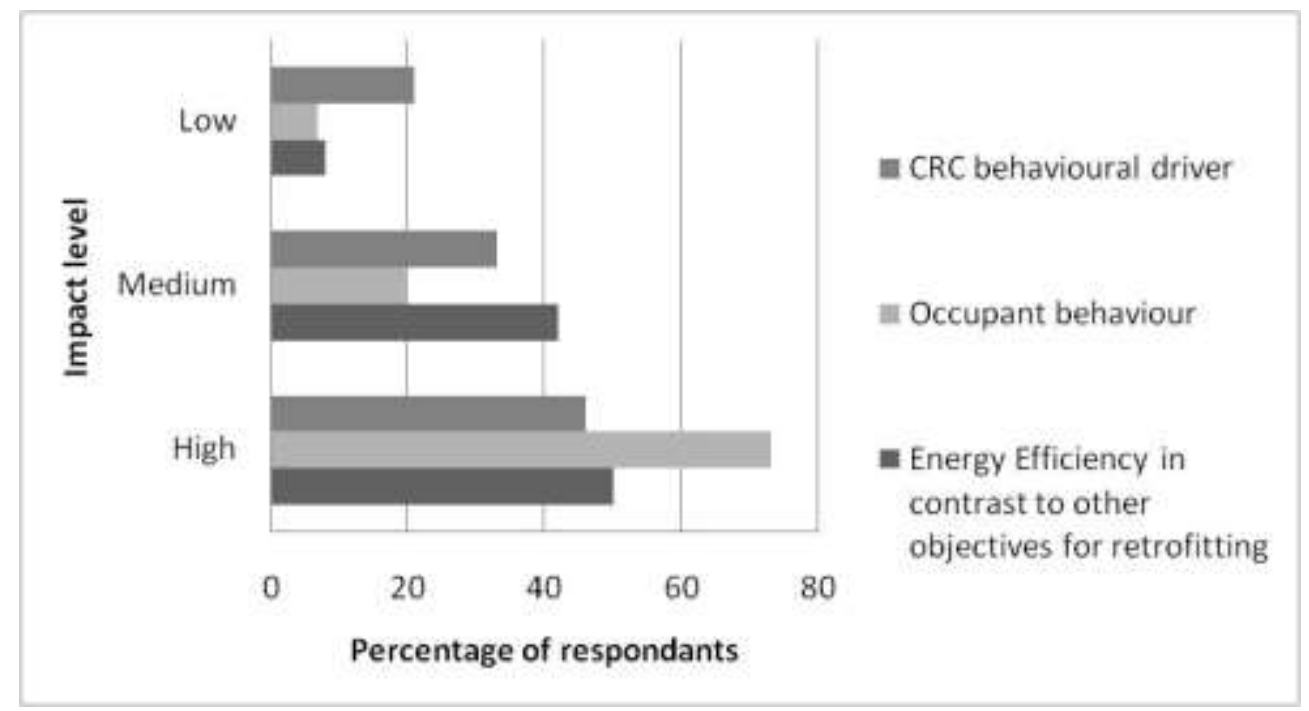

Figure 2: Impact level of influential factors for implementing EES at the operational level 
The impact of the CRC programme in the presence of other regulations is an important consideration in this study. Planning and building regulations, and English Heritage regulations have high impact on decision making according to Figure 3. The $\mathrm{CRC}$ at best has a medium impact on the decision making process.

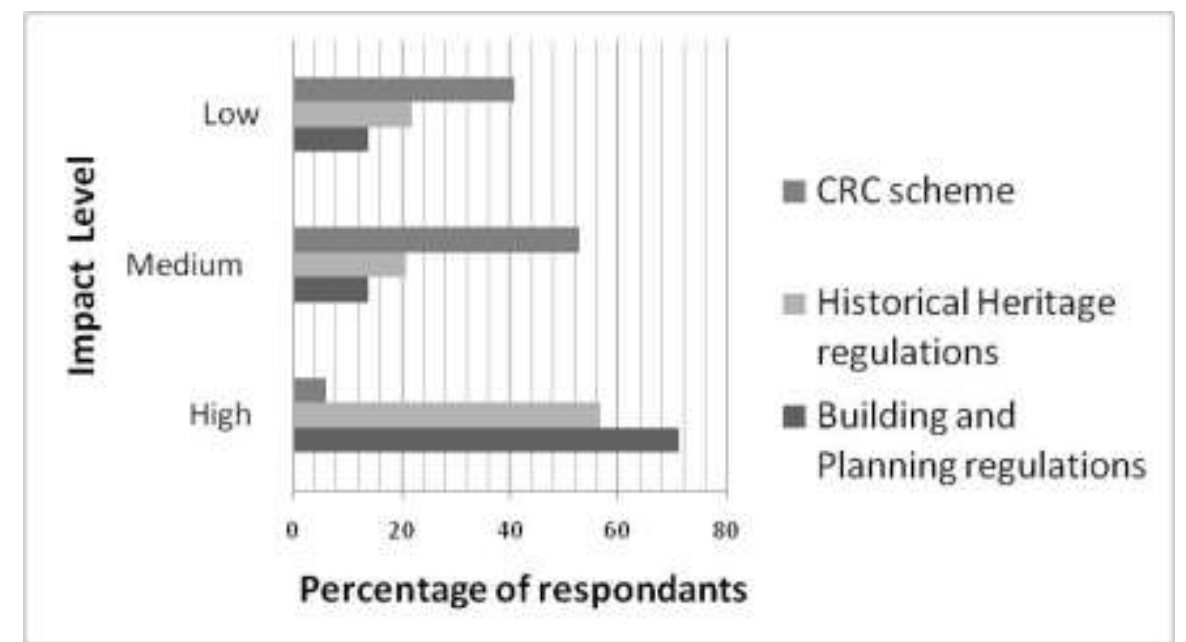

Figure 3: Impact level of influential factors for implementing EES at the administrative level

A specific analysis of the financial driver (emission allowances) was conducted focusing on Cost Benefit Analysis (CBA). Only 50\% of the colleges conduct a CBA for EES in building retrofit projects. The colleges that do not have a CBA prioritise aspects such as the rolling programme and the quality of the work in the decision making process. The lack of a CBA makes it difficult for some colleges to evaluate the benefits of the financial driver of the CRC.

In the presence of energy prices the CRC has a lesser impact on the decision making processes that include a CBA for implementing EES. 50\% of the respondents stated that savings due to rising energy price is a primary consideration in the CBA; in contrast 5\% stated the CRC tax has a high impact in the CBA (Figure 4). $75 \%$ of the respondents (from the group that conduct CBAs) stated that they take in to account the co-benefits of implementing EES.

Further discussion with the respondents resulted in identifying three factors that undermine the impact of the financial driver of the CRC: (1) the total allowance cost is marginal to the college in order to make an impact on the decision making process; (2) there is an inability to clearly state the payback period for most common measures of energy efficiency, and (3) the CRC is considered "just another tax" by the respondents, and not a financial driver to improve energy efficiency. 


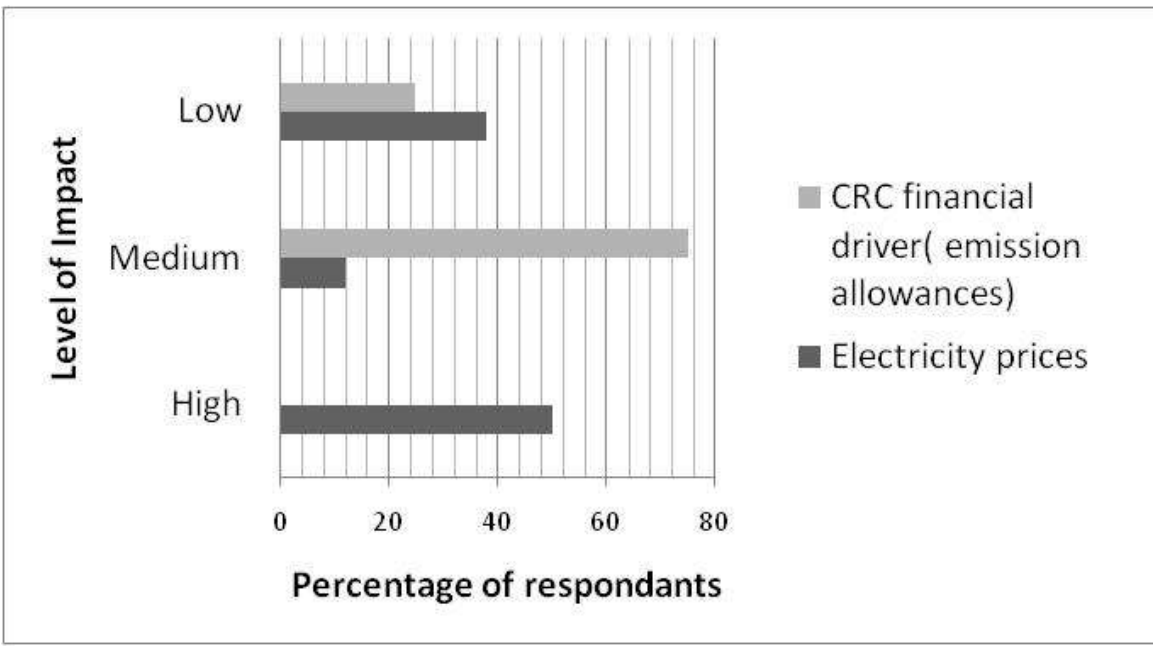

Figure 4: A comparison of the impact of electricity prices and CRC emission allowances in the $\mathrm{CBA}$

In Figure 5 organisational reputation and macroeconomic factors have a higher percentage of "high impact" responses in comparison to the CRC reputational driver. The CRC reputation driver (PLT) at best has a medium impact according to the respondents. Most respondents agreed that the PLT has very little impact in motivating the implementation of EES in existing buildings.

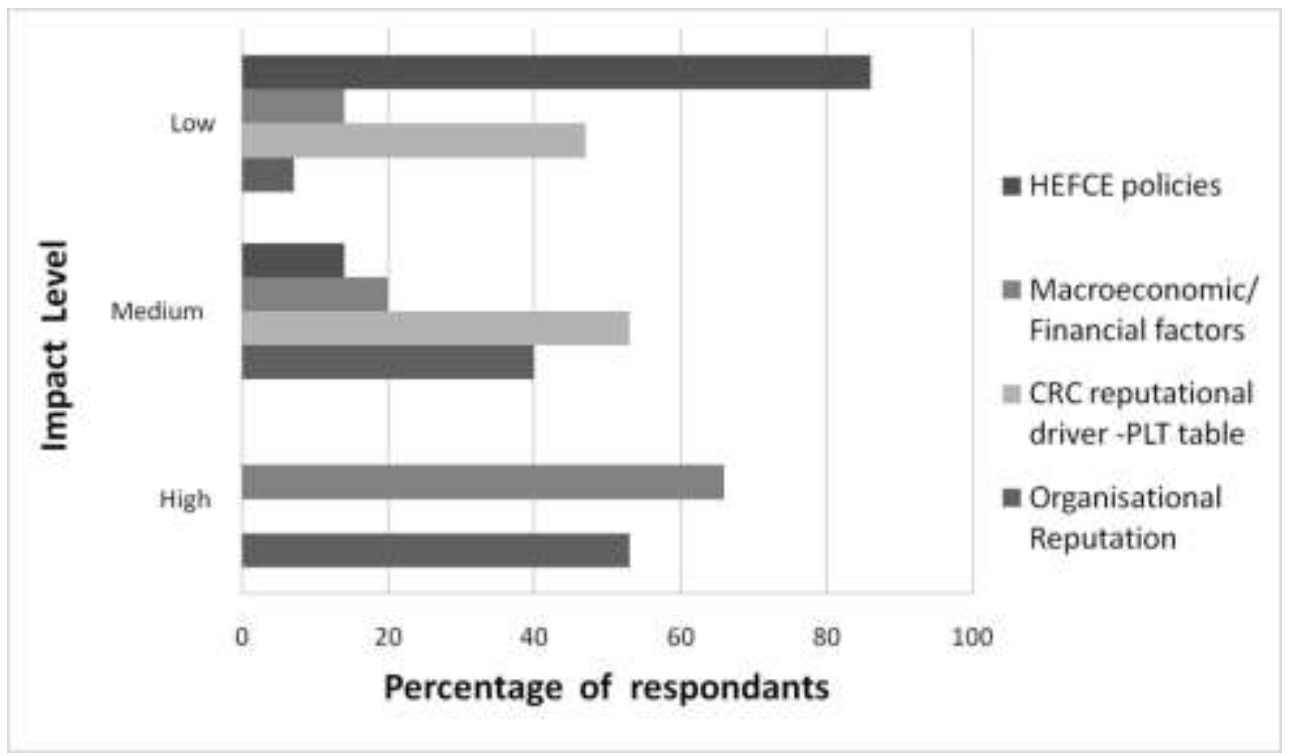

Figure 5: Impact level of influential factors for implementing EES at the strategic level 


\section{Conclusions}

The mandatory compliance aspect of the CRC makes it an important consideration in the decision making processes of the colleges as all the respondents were well aware of the $\mathrm{CRC}$ reporting structure and obligations.

The $90 \%$ coverage of all energy use to be reported under CRC contributes to providing participating organisations more options for implementing EES (though this aspect will be removed from the 2013/14 reporting year and replaced with a $2 \%$ de minimum reporting requirement, it may have an impact on comprehensive data collection of energy consumption as organisations would still have to adhere to a minimum coverage of energy use). This had been especially effective in the colleges as energy consumption in most existing buildings was not monitored comprehensively before the implementation of the CRC with the exception of College D.

As the colleges have a breakdown of their energy consumption due to monitoring and reporting requirement of the $\mathrm{CRC}$, year to year comparison of CRC supplies will help them identify the optimum allocation of EES in organisations in the future.

Mandatory reporting in the CRC is not backed by attractive incentives in order to influence the decision making process for implementing EES. For example initially the financial (emission allowances) and the reputational (PLT) driver of the CRC were tied by the proposition to recycle the revenue of CRC to participants based on the performance in the PLT. However with the removal of this aspect of the scheme the two drivers are less effective in motivating EES individually.

The CRC has had success in improving monitoring but due to technical flaws in the energy management software the data has not been utilized to implement EES. Therefore energy management software has to be improved in a user friendly manner where data can be utilised for implementing EES.

Cost of emission allowances is low in comparison to costs of improving energy efficiency. First costs of implementing EES are very high. Therefore some colleges consider EES as cost neutral or just as a cost, without considerations for possible savings (as savings from emission allowances tend to be marginal).

As analysed in the study, the CRC has not generated a significant impact during the short term since its inception. However in the long term the CRC may be successful in motivating implementation of EES by analysing time-series data of energy use patterns in buildings.

The colleges at present cooperate in reporting and in purchasing emission allowances. This is not extended to cooperation among the colleges to develop strategies for improving energy efficiency in buildings. However as the data on the energy use of Colleges is available from a single source (the CRC Coordinator for 
the colleges) it is more convenient to recover the data for informing possible partnerships to reduce first costs for implementing EES.

According to Figure 5, the PLT at best has a medium impact on decision making at strategic level. The publication of participants' ranking in the CRC makes no distinction between the type of organisation as universities, supermarkets, banks etc. However as there is a difference in energy consumption patterns between organisations, it may be useful to compare organisations that have similar factors influencing their decision making process. Therefore for a more effective impact of the reputational driver, the list of organisations published should distinguish between the types of organisations.

The main threat to the CRC is the risk of over simplification of mandatory requirements for compliance due to consultations with the participants. For example as the cap and trade aspect of the financial driver will be removed from the 2013/14 and replaced with a tax, the incentive to reduce $\mathrm{CO}_{2}$ emissions will further decrease. The only incentive for EES for the colleges will be the reduction in their tax burden.

The inability to accurately calculate benefits (especially co-benefits) from EES is also a drawback for the CRC. Benefits of EES are usually measured by calculating pay back periods. For some EESs such as photovoltaic panels, energy efficient boilers or CHP, payback periods are easily calculated using net present value. But measures such as insulation and double glazing are not used in the CBA as the payback period is difficult to calculate. The calculation for the latter measures involves sub-metering of the building which is not available or reliable in many properties. For example, the benefits of double glazing of the windows of the Fischer building of college E could not be calculated as the building shares its electricity supply with other properties.

Lack of focus on deep retrofits of participants will also make it difficult for CRC to reach its emission reduction targets. As EES are only an opportunistic and not a primary consideration, colleges resort to conventional retrofits due to difficulty in obtaining building permission, funding for deep retrofits.

\section{Acknowledgements}

I would like to acknowledge Ms. Carole Birtwhistle, the CRC coordinator and Energy Manager of the colleges, for her insight in to CRC and for the data provided on CRC compliance of the colleges. In addition, I would like to thank the Bursars and the Estate Managers for their time and cooperation for the interviews. 


\section{References}

Amstalden, R. W., M. Kost, C. Nathani and D. M. Imboden (2007). "Economic potential of energy-efficient retrofitting in the Swiss residential building sector: The effects of policy instruments and energy price expectations". Energy Policy, 35: 1819-1829.

Ansoff, H. 1. (1969). Business Strategy (Ed.). New York, N.Y.

Department of Trade and Industry (2007). "Meeting the energy challenge". Available online:

http://webarchive.nationalarchives.gov.uk/20121205174605/http:/www.decc.gov.uk/a ssets/decc/publications/white_paper_07/file39387.pdf.

Harvey, C. M. (1992). “A slow-discounting model for energy conservation”. Interfaces, 22: $47-60$.

Jacobs, B. W., V. R. Singhal and R. Subramanian (2010). “An empirical investigation of environmental performance and the market value of the firm". Journal of Operations Management, 28, 430-441.

Kelly, M. J. (2009). "Retrofitting the existing UK building stock". Building Research \& Information, 37 (2): 196-200.

Kwok, S. S. K. and E. W. M. Lee (2011). "A study of the importance of occupancy to building cooling load in prediction by intelligent approach". Energy Conversion and Management, 52: 2555-2564.

McGinnis, M. D. (2011). "An introduction to IAD and the language of the Ostrom workshop: A simple guide to a complex framework". Policy Studies Journal, 39: $169-183$.

Ostrom, E. (2005). "Understanding institutional diversity". Princeton University Press, Princeton, N.J., USA.

Ostrom, E. (2007). "Challenges and growth: the development of the interdisciplinary field of institutional analysis". Journal of Institutional Economics, 3: 239-264.

Rysanek, A. M. and R. Choudhary (2012). "Optimum building energy retrofits under technical and economic uncertainty". Energy and Buildings.

World Business Council for Sustainable Development (WBCSD) (2009). "Transforming the markets: Energy efficiency in buildings". Atar Roto Presse SA, Switzerland. 